\title{
BMJ Open Impact of a modified version of baby- led weaning on iron intake and status: a randomised controlled trial
}

\author{
Lisa Daniels, ${ }^{1,2}$ Rachael W Taylor, ${ }^{2}$ Sheila M Williams, ${ }^{3}$ Rosalind S Gibson, \\ Elizabeth A Fleming, ${ }^{1,2}$ Benjamin J Wheeler, ${ }^{4}$ Barry J Taylor, ${ }^{4}$ Jillian J Haszard, ${ }^{1}$ \\ Anne-Louise M Heath ${ }^{1}$
}

To cite: Daniels L, Taylor RW, Williams SM, et al. Impact of a modified version of babyled weaning on iron intake and status: a randomised controlled trial. BMJ Open 2018:8:e019036. doi:10.1136/ bmjopen-2017-019036

- Prepublication history and additional material for this paper are available online. To view these files, please visit the journal online (http://dx.doi. org/10.1136/bmjopen-2017019036).

Received 7 August 2017

Revised 9 March 2018

Accepted 2 May 2018
Check for updates

${ }^{1}$ Department of Human Nutrition, University of Otago, Dunedin, Otago, New Zealand

${ }^{2}$ Department of Medicine, University of Otago, Dunedin, New Zealand

${ }^{3}$ Department of Preventive and Social Medicine, University of Otago, Dunedin, New Zealand ${ }^{4}$ Department of Women's and Children's Health, University of Otago, Dunedin, New Zealand

Correspondence to

Dr Anne-Louise M Heath;

anne-louise.heath@otago.ac.nz

\section{ABSTRACT}

Objective To determine the iron intake and status of infants following a version of baby-led weaning (BLW) modified to prevent iron deficiency (Baby-Led Introduction to SolidS; BLISS) compared with those of infants following traditional spoon-feeding.

Design, participants and intervention This randomised controlled trial included 206 participants assigned to control $(n=101)$ or BLISS $(n=105)$ groups. Both groups received standard midwifery and 'Well Child' care. BLISS participants received eight additional visits (from before birth to 9 months) providing education and support on the BLISS approach to complementary feeding (ie, BLW modified to increase iron intake). The primary outcome of the BLISS study (growth) has been previously reported. This paper reports the key prespecified secondary outcomes, iron intake and iron status.

Outcome measures Intake of iron and key absorption modifiers were assessed using weighed 3-day diet records at 7 and 12 months. A venipuncture blood sample was collected at 12 months to determine plasma ferritin, haemoglobin, soluble transferrin receptor, C-reactive protein and $\alpha_{1}$-acid glycoprotein concentrations; and body iron was calculated.

Results Differences in median dietary iron intakes between the control and BLISS groups were not significant at 7 (difference $0.6 \mathrm{mg} / \mathrm{day} ; 95 \% \mathrm{Cl}-1.0$ to 2.3 ) or 12 $(-0.1 \mathrm{mg} /$ day; -1.6 to 1.4$)$ months of age. Similarly, there were no significant differences in plasma ferritin concentration (difference $-2.6 \mu \mathrm{g} / \mathrm{L} ; 95 \% \mathrm{Cl}-10.9$ to 5.8 ), body iron $(0.04 \mathrm{mg} / \mathrm{kg} ;-1.1$ to 1.2$)$ or the prevalence of depleted iron stores, early functional iron deficiency or iron deficiency anaemia (all $p \geq 0.65$ ) at 12 months of age.

Conclusions A baby-led approach to complementary feeding does not appear to increase the risk of iron deficiency in infants when their parents are given advice to offer 'high-iron' foods with each meal.

Trial registration number ACTRN12612001133820; Preresults.

\section{INTRODUCTION}

Anecdotal reports suggest that many parents are following baby-led weaning (BLW) with their infants, particularly in New Zealand, ${ }^{1}$ the $\mathrm{UK}^{2}$ and Canada. ${ }^{3}$ However, health professionals have expressed concerns about

\section{Strengths and limitations of this study}

- First randomised controlled trial to investigate the impact of a baby-led approach to complementary feeding on iron intake and biochemical iron status.

- Robust dietary assessment data provided by weighed diet records collected on non-consecutive days.

- Did not reach planned sample size, but Cls were provided to indicate the range of plausible values in the population.

- This trial cannot be used to draw conclusions about the risk of iron deficiency in infants following unmodified baby-led weaning.

this alternative approach to complementary feeding that need to be addressed. ${ }^{34}$ Infants following BLW are expected to feed themselves all of their food from the start of the complementary feeding period, ${ }^{5}$ and it has been proposed that this may increase the risk of iron deficiency if the majority of first foods offered are foods low in iron, such as fruits and vegetables, or if iron-fortified infant cereals are avoided due to their semiliquid consistency. ${ }^{6}$ A recent observational study reported that mean dietary iron intake in infants following BLW was less than half that of infants following traditional spoonfeeding. ${ }^{6}$ However, the impact of this lower iron intake on the biochemical iron status of infants has not been examined in that ${ }^{6}$ or any other study.

Iron deficiency that progresses to iron deficiency anaemia can impact on the central nervous system and development during infancy, leading to poorer cognitive and behavioural performance. ${ }^{7}$ Moreover, these impacts on infant development may not be reversible. $^{8}{ }^{9}$ It is important, therefore, to determine whether a baby-led approach can be followed without increasing the risk of iron deficiency before baby-led approaches 
can be considered an appropriate alternative to traditional complementary feeding practices.

The aim of the Baby-Led Introduction to SolidS (BLISS) study was to determine whether a modified version of BLW prevented young children from becoming overweight ${ }^{10}$ without increasing their risk of iron deficiency, growth faltering ${ }^{10}$ and choking. ${ }^{11}$ In this paper, we report the key prespecified secondary outcomes iron intake (at 7 and 12 months of age) and iron status (at 12 months) of infants following BLISS compared with traditional spoon-feeding.

\section{METHODS}

Detailed methods have been described elsewhere ${ }^{12}$ so only relevant information is included here. Adult participants gave written informed consent. Pregnant women in their third trimester of pregnancy who were booked into the Queen Mary Maternity Hospital in Dunedin, New Zealand were invited to the study between November 2012 and March 2014. Delayed cord clamping was infrequently practised in Queen Mary Maternity Hospital at the time of the study. Women were eligible if they: spoke English or Te Reo Māori (the indigenous language of New Zealand); planned to live in Dunedin, New Zealand, until their child was at least 2 years of age; and were 16 years of age or older. Women were excluded if their infant was born before 37 weeks' gestation, or had a congenital abnormality, physical condition or intellectual disability that was likely to affect their feeding or growth. Participants were randomised using random-length blocks after stratification for parity (first child, subsequent child) and maternal education (tertiary, non-tertiary), to control $(\mathrm{n}=101)$ or BLISS $(\mathrm{n}=105)$ groups by the study biostatistician. The BLISS study, and intervention, are not in any way related to the UK-based Bliss charity for 'babies born premature or sick' (www.bliss.org.uk).

\section{Intervention}

The control group participants received routine midwifery (until 6 weeks of age) and 'Well Child' care (from 6 weeks). 'Well Child Tamariki Ora' is a nationally funded programme to support and educate families with children under 5 years of age. The programme recommends exclusive breast feeding until around 6 months of age with the introduction of complementary foods at around 6 months. ${ }^{13}$

Participants in the BLISS group received routine midwifery and 'Well Child' care, and BLISS support and education from before birth (approximately 34-35 weeks' gestation) until 9 months of age. The BLISS approach was based on three key principles of BLW: exclusive milk feeding until 6 months of age, infant self-feeding from the start of complementary feeding (ie, baby-led from 6 months of age) and offering family foods as finger foods so that they can be picked up by the infant. However, BLISS also included modifications to address the three main concerns about BLW expressed by health professionals ${ }^{34}$ : iron deficiency, growth faltering ${ }^{10}$ and choking. ${ }^{11}$

The BLISS intervention comprised: (1) five contacts with a lactation consultant (from the third trimester of pregnancy to 6 months of age) to encourage and support exclusive milk feeding (ideally breast feeding) and delay the introduction of complementary foods until 6 months of age, (2) three contacts with BLISS research staff to give individualised advice on how to follow BLISS (at 5.5, 7 and 9 months of age) and (3) a range of written resources that were developed to help parents follow BLISS, ${ }^{14}$ including recipe books given at 5.5, 7 and 9 months of age, and lists of age-appropriate foods. ${ }^{12}$ Parents were encouraged to offer their child three types of finger foods at every meal: a 'high-iron' food (eg, red meat, iron-fortified infant cereal (in a hand-held way, eg, on toast)), an energy-rich food ( $>1.5 \mathrm{kcal} / \mathrm{g}$, eg, avocado, cheese) and an easy-to-eat food such as fruit or vegetables. BLISS participants were provided with complementary packets of iron-fortified infant cereal (For Baby Rice Cereal; Heinz Watties, Australia) at each of the intervention visits (5.5, 7 and 9 months). The iron content of this infant cereal was $2.2 \mathrm{mg}$ per $100 \mathrm{~g}$ of infant cereal prepared with water.

\section{Adherence}

Questionnaires were used to determine adherence to BLISS by asking parents 'how has your baby been fed solids in the past week?' when their infant was 7 and 12 months of age. Adherence to BLISS was defined as the infant feeding themselves most or all of their food in the past week.

\section{Outcome assessment}

Demographic data were collected at baseline by questionnaire, except for birth weight and gestational age which were obtained from hospital records. Research staff conducting measurement visits and administering questionnaires were blinded to group allocation. At 2, 4, $6,7,8,9$ and 12 months of age, brief feeding questionnaires were used to collect information including the age when breast feeding was stopped and/or formula feeding was started and stopped.

\section{Dietary assessment}

Weighed 3-day diet records (WDRs) were used to assess dietary intake at 7 and 12 months of age. Parent participants were given detailed instructions and provided with dietary scales (Salter Electronic, Salter Housewares, Tonbridge, UK) accurate to $\pm 1 \mathrm{~g}$. They then recorded everything their child ate and drank over three randomly assigned non-consecutive days (twoweekdays and oneweekend day) over a 3-week period. Parents were asked to record the total weight of food offered, and to collect, weigh and record all leftover food including food on the floor, baby or the tray, so that the amount of food consumed by the infant could be calculated. Any supplements consumed were also recorded. 
The WDRs were entered into Kai-culator V.1.13s (University of Otago, New Zealand), a dietary analysis program that includes dietary data from the New Zealand Food Composition Database (FOODfiles 2010, Plant and Food Research) ${ }^{15}$ commonly consumed recipes from the 2008-2009 New Zealand Adult Nutrition Survey ${ }^{16}$ and commercial infant foods collated by the research team. ${ }^{17}$ It was not possible to directly measure breast milk intake so it was assumed to be $750 \mathrm{~g}$ per day at 7 months and $448 \mathrm{~g}$ per day at 12 months based on a quadratic curve fitted to the breast milk volumes reported by Dewey et al. ${ }^{18}$ If the infant was fed both breast milk and infant formula then the gram amount of infant formula consumed was subtracted from the estimated total breast milk intake (ie, 750 or $448 \mathrm{~g}$ per day). The iron content of breast milk was assumed to be $0.07 \mathrm{mg}$ per $100 \mathrm{~g} .{ }^{15}$

Grams of red meat, grams of 'meat, fish, poultry', milligrams of haem iron ${ }^{19}$ and milligrams of phytate ${ }^{20}$ were determined using values from the literature and information from manufacturers.

\section{Biochemical assessment}

A non-fasting venous blood sample was obtained from 119 infants at 12 months of age (58\% of total study participants). Of those who did not provide a blood sample, 26 blood draws were unsuccessful, 22 had withdrawn from the study by 12 months of age, 13 could not be contacted or were living out of town and 26 parents did not provide consent for the blood test. Blood samples were drawn from an antecubital vein into a trace element-free lithium heparin anticoagulated tube $(7.5 \mathrm{~mL}$; S-Monovette, Sarstedt, Nümbrecht, Germany) and refrigerated immediately after collection. If the child was unwell, the blood test was delayed for 14 days.

Complete blood count (Sysmex XE 5000, Kobe, Japan) and plasma ferritin (Cobas 8000 unit e 602, Roche, USA) were determined on collection day by Southern Community Laboratories (Dunedin, New Zealand). Aliquots of plasma were stored at $-80^{\circ} \mathrm{C}$ until subsequent analysis of soluble transferrin receptor (sTfR), C-reactive protein (CRP) and $\alpha_{1}$-acid glycoprotein (AGP), using a Cobas C311 (Roche, USA) at the Department of Human Nutrition laboratories (University of Otago, Dunedin, New Zealand). Cut-offs of $>5 \mathrm{mg} / \mathrm{L}$ CRP and $>1 \mathrm{~g} / \mathrm{L}$ AGP defined the presence of inflammation, for example, as a result of infection. Ferritin multipliers were used to adjust ferritin concentrations to remove the influence of this inflammation. ${ }^{21}$ The sTfR values were converted to be equivalent with the Flowers assay ${ }^{22}: 1.5 \times$ Roche $\mathrm{sTfR}+0.35 \mathrm{mg} / \mathrm{L}$ and body iron $(\mathrm{mg} / \mathrm{kg})$ was calculated ${ }^{22}$ :

$$
-[\log 10(s T f r \times 1000 / \text { ferritin })-2.8229] / 0.1207 \text {. }
$$

\section{Adverse events}

Participants with biochemical results outside predefined clinical reference ranges for complete blood count indices or plasma ferritin were contacted, informed of the abnormal result and advised to visit their general practitioner for advice.

\section{Statistical analysis}

The data were analysed according to modified intention to treat. A sample size of 84 participants per group provided $80 \%$ power $(\alpha=0.05)$ to detect a difference in geometric mean plasma ferritin concentrations of $5.0 \mu \mathrm{g} / \mathrm{L} .{ }^{12}$

The proportions of infants at 7 and 12 months of age fed breast milk, infant formula or both ('mixed fed'), as well as those consuming cow's milk were determined using $\chi^{2}$ tests. All nutrient and food group data were presented as daily averages over the 3 days. As most variables were positively skewed, the data were reported as medians and lower and upper quartiles (25th and 75th). Quantile regression was used to estimate the difference between the control and BLISS groups for energy and nutrient intake, as well as dietary iron intake from each food group. Usual iron intake was determined, ${ }^{23}$ and the prevalence of inadequate iron intakes was estimated using the full-probability approach. ${ }^{24}$

Means and SDs were used to describe all of the biochemical variables except plasma ferritin, CRP and AGP, which were presented as medians and lower and upper quartiles. Differences in biochemical iron status indices were estimated using regression and were adjusted for infant age at the time of blood test, infant sex, maternal education (non-tertiary vs tertiary) and maternal parity ( 1 child vs $>1$ child, including the current pregnancy). A $\chi^{2}$ test was used to compare the number of cases and controls for each of the iron status categories, and their associated ORs.

All analyses were conducted using statistical software Stata V.13 (StataCorp).

\section{Patient and public involvement}

Our interest in this area arose in part from requests from local parenting groups for advice on how to follow BLW safely. In addition, a content analysis study in the same region indicated that some mothers who followed BLW were concerned about whether their infant was getting enough iron. ${ }^{4}$ Once the structure of the study had been designed, the intervention resources were developed taking into account parent priorities from our pilot work. ${ }^{14}$ Parents did not play a role in recruitment. Participants will be sent a lay summary of the results when they are published. Participant burden was not measured formally, but participants were given an opportunity to comment on the study in the final questionnaire. Another analysis is investigating the acceptability to parents of BLISS as an approach to infant feeding.

\section{RESULTS}

A total of 214 mother-infant pairs were randomised, of whom eight were excluded after birth $(n=5$ control, $n=3$ BLISS), providing a final sample size of 206 participants (figure 1). Of these 206 participants, 81 control and 88 BLISS participants provided data for this secondary analysis (table 1). Baseline demographic data, and age when complementary foods were introduced, are shown 


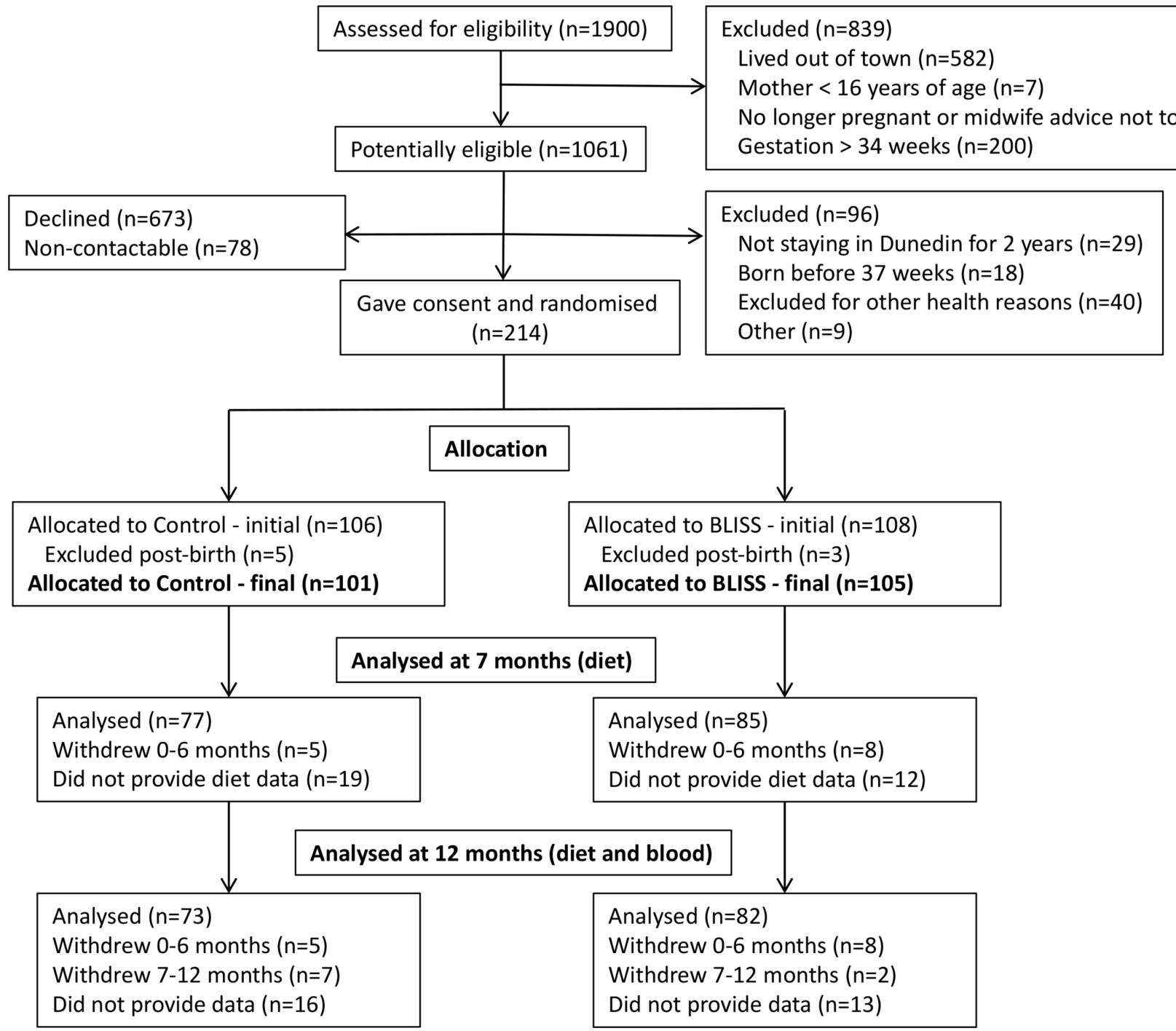

Figure 1 Flow of participants through the study. BLISS, Baby-Led Introduction to SolidS.

in table 1 . There were no differences in the characteristics of participants who were included in this analysis (ie, provided either intake or status data) compared with those not included (ie, provided neither intake nor status data) with the exception of maternal age at birth which was lower for those who did not provide data (online supplementary eTable 1 ).

Adherence to the baby-led approach was high in the BLISS group with significantly more infants feeding themselves most or all of their food in the past week at 7 ( $74 \%$ vs $19 \%$ control; $\mathrm{p}<0.001)$ and $12(77 \%$ vs $48 \%$ control; $\mathrm{p}<0.001)$ months of age.

The differences in iron intake between the BLISS group and the control group at 7 and 12 months were $0.6 \mathrm{mg}$ / day $(95 \%$ CI -1.0 to 2.3$)$ at 7 months and $-0.1 \mathrm{mg} /$ day $(-1.6$ to 1.4$)$ at 12 months (table 2$)$. In both cases, the differences were small and the CIs exclude clinically interesting differences. The same applies to intakes of the iron absorption modifiers that were measured, except for a significantly lower intake of vitamin C in BLISS (49.2 mg/ day) compared with control infants $(59.2 \mathrm{mg} /$ day $)$ at 7 months (adjusted difference $-9.7 \mathrm{mg} /$ day; $95 \%$ CI -18.4 to -0.9 ). Four participants ( $\mathrm{n}=2$ BLISS, $\mathrm{n}=2$ control) were using iron supplements at the time of the 12-month WDR but these have not been included as the supplements were started after the blood sample was collected.

There was no difference in the number of infants who were fed breast milk, formula or both, between groups at either 7 or 12 months (online supplementary eTable 2). There were no significant differences in estimated breast milk or infant formula intake between groups at 7 (breast milk difference $0.0 \mathrm{~g}$ /day; $95 \%$ CI -5.1 to 5.1 ; $\mathrm{p}=1.00$; infant formula difference $216 \mathrm{~g}$ / day; -97.2 to 530 ; $\mathrm{p}=0.17$ ) or 12 (breast milk difference $0.0 \mathrm{~g}$ /day; $95 \% \mathrm{CI}$ -0.1 to $0.1 ; \mathrm{p}=0.94$; infant formula difference $-85 \mathrm{~g} /$ day; -277 to $107 ; p=0.38$ ) months of age and therefore no differences between groups in the contribution of infant milks to iron intake (all $\mathrm{p}>0.17$ ).

BLISS infants obtained significantly more iron from 'breads and cereals', 'red meat', 'dairy' and 'legumes, nuts, seeds and eggs' than control infants at 7 months of age (table 3). For all these food groups, except 'breads 
Table 1 Characteristics of participants who provided intake data at 7 and/or 12 months of age or biochemical data at 12 months of age

\section{Control ( $n=81)$ BLISS $(n=88)$}

Maternal and household variables

Maternal age at birth (years), $\quad 32.2$ (5.8) $\quad 31.7$ (4.8)

mean (SD)

\begin{tabular}{|c|c|c|}
\hline \multicolumn{3}{|l|}{ Maternal parity } \\
\hline First child & $32(40)$ & $37(42)$ \\
\hline Two children & $27(33)$ & $37(42)$ \\
\hline Three or more children & $22(27)$ & $14(16)$ \\
\hline \multicolumn{3}{|l|}{ Maternal ethnicity } \\
\hline NZ European & $70(87)$ & $71(80)$ \\
\hline Māori & $6(7)$ & $8(9)$ \\
\hline Other & $5(6)$ & $9(10)$ \\
\hline \multicolumn{3}{|l|}{ Maternal education } \\
\hline School only & $23(28)$ & $26(30)$ \\
\hline Postsecondary & $13(16)$ & $20(22)$ \\
\hline University & $45(56)$ & $42(48)$ \\
\hline \multicolumn{3}{|l|}{ Household deprivation* } \\
\hline 1-3 (low) & $24(30)$ & $25(28)$ \\
\hline $4-7$ & $37(45)$ & $46(53)$ \\
\hline 8-10 (high) & $20(25)$ & $17(19)$ \\
\hline \multicolumn{3}{|l|}{ Infant variables } \\
\hline \multicolumn{3}{|l|}{ Sex } \\
\hline Female & $37(46)$ & $50(57)$ \\
\hline Male & $44(54)$ & $38(43)$ \\
\hline $\begin{array}{l}\text { Infant birth weight }(\mathrm{g}) \text {, mean } \\
\text { (SD) }\end{array}$ & $3510(453)$ & $3496(448)$ \\
\hline $\begin{array}{l}\text { Infant gestational age at } \\
\text { birth (weeks), mean (SD) }\end{array}$ & $39.5(1.2)$ & $39.7(1.0)$ \\
\hline \multicolumn{3}{|c|}{ Complementary feeding variables } \\
\hline $\begin{array}{l}\text { Age complementary foods } \\
\text { were introduced (weeks), } \\
\text { mean (SD) }\end{array}$ & $22.6(3.1)$ & $24.6(3.2)^{\star \star \star}$ \\
\hline $\begin{array}{l}\text { Complementary foods } \\
\text { delayed to } 6 \text { months of age }\end{array}$ & 15 (18) & $58(66)^{\star \star \star}$ \\
\hline
\end{tabular}

Data presented as n (\%), unless otherwise stated.

*Household deprivation categorised using the NZDep2013 scale in which decile 1 indicates the lowest level of deprivation and 10 indicates the highest. ${ }^{44}$

*** $\mathrm{P}<0.001$.

BLISS, Baby-Led Introduction to SolidS; NZ European, New

Zealand European.

and cereals', this reflected the greater proportion of BLISS infants consuming these foods (online supplementary eTable 3). However, the differences in iron contribution were small (eg, adjusted difference $0.1 \mathrm{mg}$ iron/ day from red meat; $95 \%$ CI 0.01 to 0.1 ) in comparison with the Average Requirement of $5.0 \mathrm{mg} /$ day $^{25}$ and therefore not likely to be clinically significant. None of the differences apparent at 7 months remained at 12 months, and although BLISS infants did receive significantly less iron from 'vegetables' than control infants at 12 months, the actual difference was very small $(-0.1 \mathrm{mg}$ iron/day; $95 \%$ CI -0.2 to -0.0 ) (table 3 ).

BLISS specifically encouraged consumption of 'highiron' foods such as red meat and iron-fortified infant cereal from the start of complementary feeding. BLISS infants were introduced to 'red meat' at the same age as control infants (28.1 weeks, 27.9 weeks, $\mathrm{p}=0.74$ ). Although significantly more BLISS than control infants consumed 'red meat' at 7 months of age (76\%, 55\%; eTable 3), intakes were similarly low for consumers in both groups (BLISS $3.2 \mathrm{~g} /$ day, control $3.8 \mathrm{~g} /$ day; online supplementary eTable 4). BLISS infants began consuming 'iron-fortified infant cereal' approximately 2 weeks later than control infants (25.4 weeks, 23.7 weeks, $\mathrm{p}=0.008$ ). Interestingly, more BLISS infants were consuming 'iron-fortified infant cereal' by 7 months of age (73\%, 51\% control) (online supplementary eTable 3 ), but the median amounts consumed were very small (BLISS $1.7 \mathrm{~g} / \mathrm{day}$, control $4.0 \mathrm{~g} /$ day) (online supplementary eTable 4 ). At 12 months, there were no significant differences in the number of consumers of 'iron-fortified infant cereal' or 'red meat', or in the amount consumed (online supplementary eTables 5 and 6).

The prevalence of inadequate iron intakes was high at $74 \%$ for both groups at 7 months of age, but considerably lower by 12 months ( $23 \%$ control, $26 \%$ BLISS).

The difference between the BLISS and control groups for plasma ferritin was $-2.6 \mu \mathrm{g} / \mathrm{L}(-10.9,5.8)$, and not statistically significant, although the lower (and upper) confidence limits do not rule out clinically meaningful effects. Differences between the groups for the other biochemical indicators of iron status were small and not statistically significant (all p $>0.55$ ) (table 4 ). Few participants had signs of inflammation/infection ( $n=8$ control, $\mathrm{n}=11$ BLISS). The majority of infants in both groups were iron sufficient (83\% control, 83\% BLISS), although 5\% control and 7\% BLISS presented with iron-deficiency anaemia (table 4). Similar numbers had anaemia other than iron deficiency anaemia (13\% BLISS, 10\% control; $\mathrm{p}=0.78)$.

Thirty-four participants had at least one biochemical value (not necessarily iron-related) outside the expected reference range for their age and were advised to contact their general practitioner for follow-up ( $n=19$ control, $\mathrm{n}=15$ BLISS).

\section{DISCUSSION}

We observed no significant differences in iron intake or status between infants following a baby-led approach to complementary feeding that had been modified to address concerns regarding iron intake, and infants following traditional spoon-feeding. However, iron intakes were low in both groups at 7 months ( $74 \%$ of infants at risk of inadequate intakes) and $17 \%$ had suboptimal iron status at 12 months. 
Table 2 Intake of iron and key absorption modifiers at 7 and 12 months of age from complementary foods and infant milks ${ }^{*}$

\begin{tabular}{|c|c|c|c|c|}
\hline & Control & BLISS & Difference $(95 \% \mathrm{Cl}) \dagger$ & $P$ values \\
\hline 7 months of age & $n=77$ & $n=85$ & & \\
\hline Energy (kJ/day), mean (SD) & $2862(548)$ & $2996(613)$ & $145(-31.2$ to 321$)$ & 0.11 \\
\hline $\begin{array}{l}\text { Energy from complementary foods only (kJ/ } \\
\text { day) } \ddagger \text {, mean (SD) }\end{array}$ & $672(506)$ & 799 (595) & $144(-26.2$ to 314$)$ & 0.10 \\
\hline Dietary iron (mg/day) & $2.7(1.3,6.9)$ & $3.0(1.5,7.3)$ & $0.6(-1.0$ to 2.3$)$ & 0.46 \\
\hline $\begin{array}{l}\text { Dietary iron from complementary foods only } \\
\text { (mg/day)§ }\end{array}$ & $1.0(0.5,2.2)$ & $1.2(0.7,2.0)$ & $0.2(-0.2$ to 0.6$)$ & 0.34 \\
\hline Haem iron (mg/day) & $0.0(0.0,0.1)$ & $0.0(0.0,0.1)$ & $0.0(-0.0$ to 0.1$)$ & 0.10 \\
\hline Non-haem iron (mg/day) & $2.6(1.3,6.9)$ & $2.9(1.4,7.3)$ & $0.4(-1.3$ to 2.0$)$ & 0.67 \\
\hline Meat, fish, poultry (g/day) & $2.8(0.0,11.1)$ & $4.3(1.4,8.8)$ & $1.3(-1.9$ to 4.4$)$ & 0.42 \\
\hline Phytate (mg/day) & $36(16.3,75.2)$ & $45(23.0,77.6)$ & $4.2(-15.0$ to 23.4$)$ & 0.67 \\
\hline Phytate:iron molar ratio & $1.0(0.4,2.3)$ & $1.3(0.6,2.7)$ & $0.4(-0.2$ to 1.0$)$ & 0.18 \\
\hline Vitamin C (mg/day) & $59.2(41.7,75.6)$ & $49.2(38.3,67.9)$ & $-9.7(-18.4$ to -0.9$)$ & 0.032 \\
\hline 12 months of age & $\mathrm{n}=68$ & $\mathrm{n}=75$ & & \\
\hline Energy (kJ/day), mean (SD) & $3573(776)$ & $3623(1048)$ & 109 (-191 to 409$)$ & 0.48 \\
\hline $\begin{array}{l}\text { Energy from complementary foods only (kJ/ } \\
\text { day) } \ddagger \text {, mean (SD) }\end{array}$ & $2400(848)$ & $2527(1183)$ & $195(-142$ to 533$)$ & 0.25 \\
\hline Dietary iron (mg/day) & $5.3(3.1,8.4)$ & $4.7(3.1,7.3)$ & $-0.1(-1.6$ to 1.4$)$ & 0.87 \\
\hline $\begin{array}{l}\text { Dietary iron from complementary foods only } \\
\text { (mg/day)§ }\end{array}$ & $3.2(2.3,4.6)$ & $3.2(2.5,4.1)$ & $-0.0(-0.6$ to 0.6$)$ & 0.94 \\
\hline Haem iron (mg/day) & $0.2(0.1,0.3)$ & $0.2(0.1,0.3)$ & 0.0 (-0.0 to 0.1$)$ & 0.57 \\
\hline Non-haem iron (mg/day) & $5.0(2.9,8.1)$ & $4.5(2.9,7.0)$ & $-0.1(-1.7$ to 1.4$)$ & 0.85 \\
\hline Meat, fish, poultry (g/day) & $19.3(7.9,33.6)$ & $19.3(11.2,31.1)$ & $-1.4(-9.0$ to 6.2$)$ & 0.72 \\
\hline Phytate (mg/day) & $187(118,310)$ & $229(152,274)$ & $37(-20.4$ to 94.8$)$ & 0.20 \\
\hline Phytate:iron molar ratio & $3.8(2.3,6.2)$ & $4.3(2.8,6.5)$ & $0.6(-0.7$ to 1.9$)$ & 0.35 \\
\hline Vitamin C (mg/day) & $48.1(39.4,69.5)$ & $50.4(36.6,61.4)$ & $0.4(-9.4$ to 10.3$)$ & 0.93 \\
\hline
\end{tabular}

Bold indicates a statistically significant difference at $p<0.05$.

Data presented as median (25th, 75th percentile), unless otherwise stated.

*Intake reported during the 3-day weighed diet records collected at 7 and 12 months of age.

†Difference adjusted for infant age (in days) and sex, and maternal education and parity.

łExcludes energy from breast milk and infant formula.

§Excludes iron from breast milk and infant formula.

ๆCalculated as [phytate (mg)/660]/[iron (mg)/55.9].

BLISS, Baby-Led Introduction to SolidS.

Although many parents are choosing to follow BLW with their infant, ${ }^{1-3}$ we know almost nothing about what these infants are eating, and how this might impact their health. Only one small observational study has evaluated intake in infants following unmodified BLW compared with age-matched and sex-matched infants following traditional spoon-feeding. ${ }^{6}$ In that study, despite similar energy intakes, BLW infants had significantly lower intakes of iron than spoon-fed infants $(1.6 \mathrm{mg} /$ day vs $3.6 \mathrm{mg} /$ day, $\mathrm{p}<0.001)$. By contrast, we found no difference in iron intakes in our study groups, and BLISS infants were consuming a median of $3.0 \mathrm{mg} /$ day of iron, suggesting that encouraging the intake of 'high-iron' foods as part of a baby-led approach to complementary foods was effective in improving iron intakes.

Our BLISS intervention recommended that 'high-iron' foods, particularly red meat and iron-fortified infant cereal, should be offered at every meal, from the start of the complementary feeding period. Red meat is high in bioavailable haem iron, ${ }^{26}$ and a higher intake has been associated with higher serum ferritin concentrations in toddlers, ${ }^{27}$ and higher haemoglobin concentrations in very young children. ${ }^{28}$ Similarly, iron-fortified infant cereal is high in iron and consumption has been shown to prevent iron-deficiency anaemia. ${ }^{29}$ In the current study, significantly more BLISS than control infants were consuming red meat at 7 months. This was in contrast to an observational study suggesting that infants following unmodified BLW were no more likely to consume red meat than spoon-fed infants. ${ }^{6}$ However, actual intakes were small in both groups, as they were for iron-fortified infant cereal. Other studies have also demonstrated relatively low intakes of both red meat ${ }^{30}$ and iron-fortified foods ${ }^{31}$ in infants and toddlers. Therefore, further 
Table 3 Iron from complementary foods at 7 and 12 months of age (consumers and non-consumers) ${ }^{\star} \dagger$

\begin{tabular}{|c|c|c|c|c|c|c|}
\hline & \multicolumn{2}{|l|}{ Control } & \multicolumn{2}{|l|}{ BLISS } & \multirow[b]{2}{*}{ Difference $(95 \% \mathrm{Cl}) \neq$} & \multirow[b]{2}{*}{ P values } \\
\hline & mg/day & $\% \S$ & $\mathrm{mg} / \mathrm{day}$ & $\% \S$ & & \\
\hline 7 months of age & $\mathrm{n}=77$ & & $\mathrm{n}=85$ & & & \\
\hline Vegetables & $0.16(0.0,0.4)$ & $17(9,25)$ & $0.10(0.0,0.2)$ & $8.4(6,17)$ & $-0.1(-0.1$ to 0.0$)$ & 0.07 \\
\hline Fruit and fruit juice & $0.13(0.0,0.2)$ & $11(5,24)$ & $0.09(0.0,0.2)$ & $7.2(3,12)$ & $-0.0(-0.1$ to 0.0$)$ & 0.19 \\
\hline Iron-fortified infant cereal & $0.08(0.0,0.7)$ & $7.9(0,54)$ & $0.19(0.0,0.5)$ & $19(0,43)$ & 0.1 (-0.1 to 0.3$)$ & 0.25 \\
\hline Breads and cereals & $0.09(0.0,0.3)$ & $7.2(2,26)$ & $0.26(0.1,0.4)$ & $23(10,35)$ & 0.2 (0.1 to 0.2$)$ & $<0.001$ \\
\hline Red meat ${ }^{\star \star}$ & $0.01(0.0,0.2)$ & $1.9(0,14)$ & $0.06(0.0,0.2)$ & $7.2(1,16)$ & 0.1 (0.0 to 0.1$)$ & 0.010 \\
\hline Miscellaneous $† \dagger$ & $0.01(0.0,0.1)$ & $1.1(0,6)$ & $0.01(0.0,0.1)$ & $1.3(0,6)$ & 0.0 (-0.0 to 0.0$)$ & 0.75 \\
\hline Dairy & $0.00 \ddagger \ddagger(0.0,0.0)$ & $0.1(0,0.4)$ & $0.00(0.0,0.0)$ & $0.5(0,2)$ & $0.0(0.0$ to 0.0$)$ & 0.010 \\
\hline $\begin{array}{l}\text { Legumes, nuts, seeds and } \\
\text { eggs }\end{array}$ & $0.00(0.0,0.0)$ & $0.0(0,2)$ & $0.04(0.0,0.1)$ & $4.5(1,11)$ & 0.0 (0.0 to 0.1$)$ & 0.001 \\
\hline Other meat§§ & $0.00(0.0,0.0)$ & $0.0(0,3)$ & $0.00(0.0,0.0)$ & $0.4(0,4)$ & $0.0(-0.0$ to 0.0$)$ & 0.57 \\
\hline 12 months of age & $n=68$ & & $\mathrm{n}=75$ & & & \\
\hline Breads and cereals & $0.84(0.5,1.6)$ & $32(16,48)$ & $1.10(0.6,1.8)$ & $38(27,50)$ & $0.2(-0.2$ to 0.5$)$ & 0.26 \\
\hline Vegetables & $0.38(0.2,0.5)$ & $11(6,16)$ & $0.29(0.1,0.5)$ & $8.9(4,14)$ & $-0.1(-0.2$ to -0.0$)$ & 0.027 \\
\hline Miscellaneous †† & $0.32(0.1,0.6)$ & $9.8(4,18)$ & $0.18(0.1,0.5)$ & $5.7(2,17)$ & $-0.1(-0.3$ to 0.0$)$ & 0.05 \\
\hline Fruit and fruit juice & $0.27(0.2,0.5)$ & $8.3(5,13)$ & $0.32(0.2,0.5)$ & $10(5,14)$ & $0.0(-0.1$ to 0.1$)$ & 0.33 \\
\hline Other meat§§ & $0.17(0.1,0.3)$ & $5.5(2,9)$ & $0.17(0.1,0.3)$ & $5.1(1,4)$ & $-0.0(-0.1$ to 0.1$)$ & 0.94 \\
\hline $\begin{array}{l}\text { Legumes, nuts, seeds and } \\
\text { eggs }\end{array}$ & $0.10(0.0,0.3)$ & $2.8(0,10)$ & $0.16(0.0,0.4)$ & $4.6(1,10)$ & $0.0(-0.0$ to 0.1$)$ & 0.28 \\
\hline Red meat $^{\star \star}$ & $0.09(0.0,0.3)$ & $2.5(0,11)$ & $0.15(0.0,0.4)$ & $3.8(0,12)$ & 0.1 (-0.1 to 0.2$)$ & 0.40 \\
\hline Dairy & $0.06(0.0,0.1)$ & $1.5(1,4)$ & $0.05(0.0,0.1)$ & $1.7(0,4)$ & $-0.0(-0.0$ to 0.0$)$ & 0.81 \\
\hline Iron-fortified infant cereal & $0.00(0.0,0.0)$ & $0.0(0,0)$ & $0.00(0.0,0.1)$ & $0.0(0,5)$ & - & - \\
\hline
\end{tabular}

Bold indicates a statistically significant difference at $p<0.05$.

Data presented as median (25th, 75th percentile).

*Intake reported during the 3-day weighed diet records collected at 7 and 12 months of age.

†Ordered from highest to lowest contributor of iron to the intakes of the control group.

‡Difference in median iron (mg/day) intake between groups: negative values represent lower values in BLISS than in control, positive values

represent higher values in BLISS than in control, adjusted for infant age (in days) and sex, and maternal education and parity.

§Data expressed as median percentages (NB: mean percentages added to $100 \%$ of total iron intakes from complementary foods).

|Breads and cereals other than iron-fortified infant cereals.

${ }^{* *}$ Red meat defined as: beef, lamb, mutton, venison.

††Miscellaneous defined as: fats, sugar, sweet foods, herbs and spices, sauces, spreads, beverages, etc.

$\ddagger \ddagger W h e r e$ the median intake is 0.00 , this has occurred because more than half of the infants did not consume this food. Some infants did consume these foods, however; so, it was possible for differences in intake to be significant. Similarly, the difference is reported as 0.00 if it is smaller than 0.05 and therefore rounds down to 0.00 .

$\S \S$ Other meat defined as: fish, poultry, pork, processed meats.

BLISS, Baby-Led Introduction to SolidS.

research is required to determine whether a more intensive intervention can feasibly increase the amount of these important iron sources consumed by both spoon-fed and baby-led infants.

Concern has been expressed regarding dietary exposure to inorganic arsenic through infant rice cereals and the potential health risks associated with high intakes in very young children. ${ }^{32}$ Intakes of $3.0 \mu \mathrm{g} / \mathrm{kg}$ body weight per day have been estimated to increase the incidence of lung cancer by $0.5 \%,{ }^{33}$ but the European Food Safety Authority has estimated that a 6-month-old infant would have to consume $90 \mathrm{~g}$ of rice-based cereal per day in order to be exposed to a level of inorganic arsenic of approximately half that level $(1.63 \mu \mathrm{g} / \mathrm{kg}$ body weight $) .{ }^{32}$ Given the maximum average intake in the current study was only $7.2 \mathrm{~g}$ per day of infant rice cereal, and the maximum observed intake was $75 \mathrm{~g}$ per day, it seems very unlikely that high intakes of inorganic arsenic are an issue in this population, even when consumption of iron-fortified rice cereal is encouraged.

There was a high proportion ( $74 \%$ of both groups) of infants at risk of inadequate iron intakes at 7 months of age. Unfortunately, we do not have a measure of iron status at 7 months to determine whether this high prevalence of inadequate intake is reflected in poor iron status. However, at 12 months of age, the risk of inadequate intakes had decreased (23\% of controls, $26 \%$ of BLISS). It is possible that this high prevalence at 7 months of age 
Table 4 Iron status indicators and categories at 12 months of age

\begin{tabular}{|c|c|c|c|c|}
\hline & Control $(n=59)$ & BLISS $(n=60)$ & Difference $(95 \% \mathrm{Cl})^{*}$ & $P$ values \\
\hline Haemoglobin (g/dL), mean (SD) & $11.7(0.84)$ & $11.6(0.89)$ & $-0.08(-0.40$ to 0.23$)$ & 0.59 \\
\hline Plasma ferritin $(\mu \mathrm{g} / \mathrm{L}) \dagger$ & $28.9(18.5,47.4)$ & $27.0(19.5,42.1)$ & $-2.6(-10.9$ to 5.8$)$ & 0.55 \\
\hline Soluble transferrin receptor (mg/L), mean (SD) & $7.6(2.0)$ & $7.4(2.7)$ & $-0.2(-1.0$ to 0.7$)$ & 0.70 \\
\hline Body iron (mg/kg)‡, mean (SD) & $3.3(3.1)$ & $3.3(2.9)$ & $0.04(-1.1$ to 1.2$)$ & 0.95 \\
\hline C-reactive protein (mg/L) & $0.1(0.0,0.5)$ & $0.2(0.1,0.5)$ & $-0.02(-0.2$ to 0.2$)$ & 0.86 \\
\hline$\alpha_{1}$-Acid glycoprotein (g/L) & $0.6(0.4,0.8)$ & $0.6(0.5,0.95)$ & $0.04(-0.1$ to 0.2$)$ & 0.56 \\
\hline Iron status categories, n (\%) & & & OR $(95 \% \mathrm{Cl}) \S$ & $P$ values \\
\hline Iron sufficient & $49(83)$ & $50(83)$ & 1.0 & - \\
\hline Iron depleted ${ }^{\star *}$ & $3(5)$ & $2(3)$ & $1.5(0.2$ to 9.6$)$ & 0.65 \\
\hline Early functional iron deficiency†† & $4(7)$ & $4(7)$ & $1.0(0.2$ to 4.3$)$ & 0.98 \\
\hline Iron deficiency anaemiał‡ & $3(5)$ & $4(7)$ & 0.8 (0.2 to 3.6$)$ & 0.74 \\
\hline
\end{tabular}

Data presented as median (25th, 75th percentile), unless otherwise stated.

${ }^{*}$ Difference adjusted for infant age (in days) and sex, and maternal education and parity: negative values represent lower values in BLISS than in control, positive values represent higher values in BLISS than in control.

†Ferritin adjusted for inflammation using multipliers proposed by Thurnham et al. ${ }^{21}$

$\ddagger$ Łody iron calculation $(\mathrm{mg} / \mathrm{kg})=-\left[\log 10\left(\mathrm{sTfRx} 1000 /\right.\right.$ ferritin)-2.8229]/0.1207 from Cogswell et al. ${ }^{22}$

§OR of control relative to BLISS.

IDefined as body iron $\geq 0 \mathrm{mg} / \mathrm{kg}$, haemoglobin $\geq 11.0 \mathrm{~g} / \mathrm{dL}$ and plasma ferritin $\geq 15 \mu \mathrm{g} / \mathrm{L}$.

${ }^{* *}$ Defined as plasma ferritin $<15 \mu \mathrm{g} / \mathrm{L}$, in the absence of early functional iron deficiency and iron deficiency anaemia.

††Defined as body iron $<0 \mathrm{mg} / \mathrm{kg}$ and haemoglobin $\geq 11.0 \mathrm{~g} / \mathrm{dL}$.

$\ddagger \ddagger$ Defined as body iron $<0 \mathrm{mg} / \mathrm{kg}$ and haemoglobin $<11.0 \mathrm{~g} / \mathrm{dL}$.

BLISS, Baby-Led Introduction to SolidS.

may be due to the cut-offs available for determining the risk of inadequate iron intakes-currently, there is no specific cut-off for infants less than 8 months of age that has the Institute of Medicine probabilities of inadequacy that are needed in order to calculate the prevalence of inadequacy. ${ }^{34}$

The BLISS study focused on iron-deficiency anaemia, but $10 \%$ of control infants and $13 \%$ of BLISS infants were diagnosed as having anaemia that was not concurrent with iron deficiency. Non-iron-deficient anaemia can be caused by a wide range of conditions, including infection (eg, with malaria, HIV or hookworm), folate or vitamin $\mathrm{B}_{12}$ deficiency, or genetic disorders such as thalassemia and sickle cell anaemia. ${ }^{35}$ We took care to minimise rates of infection in our study design, and malaria, HIV and hookworm are extremely rare in this age group in New Zealand. Similarly, no participant had a mean cell $>86 \mathrm{fL}$ which would be indicative of the megaloblastic anaemia of folate or vitamin $B_{12}$ deficiency. ${ }^{36}$ We cannot rule out haemoglobinopathies as a cause of anaemia for some of the infants, but these would be fairly rare in this population. An alternative explanation for the high proportion of other anaemia could be the cut-off used for defining anaemia $(<110 \mathrm{~g} / \mathrm{L}) .^{35}{ }^{36}$ This value has been extrapolated from older age groups, ${ }^{37}$ and there has been some discussion as to whether a lower cut-off may be more appropriate in this age group. ${ }^{38}$

The current study suggests that when parents following a baby-led approach to complementary feeding are given advice to offer infants 'high-iron' foods with every meal, their iron status is similar to control infants. This finding is important given health professionals' concerns that baby-led approaches to complementary feeding may increase the risk of iron deficiency, ${ }^{34}$ and the observation that infants following unmodified BLW have significantly lower iron intakes. ${ }^{6}$ Although we did not reach our planned sample size, it is important to note the most extreme difference in plasma ferritin concentration consistent with the data was $-10.9 \mu \mathrm{g} / \mathrm{L}$ (ie, the lower confidence limit for the difference). This suggests that, in response to a BLISS intervention, the control group's median plasma ferritin concentration might, at most, fall to $18.0 \mu \mathrm{g} / \mathrm{L}$ - a value above the cut-offs usually associated with deficiency (ie, 12 or $15 \mu \mathrm{g} / \mathrm{L}$ ). The data are also consistent with plasma ferritin rising to $34.7 \mu \mathrm{g} / \mathrm{L}$ (applying the upper confidence limit). The confidence limits for the differences in dietary iron intake at 7 and 12 months of age suggest that any differences may be too small to be of clinical interest with plausible ranges of -1 to 2.3 at 7 months and -1.6 to 1.4 at 12 months.

Our study has a number of strengths including being the first randomised controlled trial to investigate the impact of a baby-led approach to complementary feeding on iron intake and status. We collected robust dietary data using three non-consecutive days of weighed diet records. As infants often do not eat all of the food offered to them, we asked parents to weigh the food before and after eating (including food that was no longer on the surface on which it was originally offered) to ensure we had as accurate a representation of actual consumption as was possible in a free-living population. The study had limited power to detect differences of $5.0 \mu \mathrm{g} / \mathrm{L}$ in 
geometric mean plasma ferritin concentrations because blood samples were obtained from 119 participants rather than the planned 168. However, the CIs enable the reader to see the range of plausible differences in plasma ferritin between the groups. Also, estimated breast milk volumes were used. This approach is commonly used when other methods are not feasible ${ }^{3139-43}$ but does mean that we do not have specific intake values for individuals. In particular, although the estimated breast milk volumes were determined in infants who were consuming complementary foods, ${ }^{18}$ we cannot rule out the possibility that BLISS had different effects on the amount of breast milk consumed. However, there was no evidence in the current study that BLISS impacted on the amount of infant formula consumed at 7 and 12 months of age. Finally, it was not considered ethical to randomise participants to follow an unmodified version of BLW because of concerns about its safety. ${ }^{34}$ Therefore, the results should not be used to make conclusions about the iron status of infants following unmodified BLW.

\section{CONCLUSIONS}

There was no evidence of a difference in iron intakes and status between spoon-fed infants and infants following this modified version of BLW in which parents were given advice to offer 'high-iron' foods with each meal. This suggests that a baby-led approach can be used without impacting negatively on iron status. However, it is important to note that this study assessed a modified version of BLW so no conclusions can be made about the risk of iron deficiency in infants following unmodified BLW.

Acknowledgements The authors would like to acknowledge all the families who participated in the BLISS study, as well as the research staff involved from the Departments of Human Nutrition and Medicine at the University of Otago.

Contributors A-LMH and RWT conceived and designed the research. LD contributed to the design of the iron-related components of the research, collected data, and prepared the first full and subsequent drafts of this manuscript. SMW and JJH advised on study design and performed statistical analyses. RSG, EAF, BJW and BJT provided expert input into the design of the study and ongoing advice and support. All authors made an important intellectual contribution to this manuscript, and approved the final manuscript as submitted.

Funding This work was supported by Meat \& Livestock Australia, Lottery Health Research, Karitane Products Society, Perpetual Trustees, the University of Otago and the New Zealand Federation of Women's Institutes. Heinz Wattie's Limited provided baby rice cereal for participants in the intervention group. Part of RWT's salary is from a Karitane Products Society (KPS) Fellowship that is paid via the University of Otago. LD was supported by a University of Otago Doctoral Scholarship, and a University of Otago Postgraduate Publishing Bursary.

Disclaimer The funders provided funds only and played no role in the study design, development of the study aims, carrying out the study or the analysis or interpretation of the results.

Competing interests None declared.

Patient consent Not required.

Ethics approval The Lower South Regional Ethics Committee (LRS/11/09/037), New Zealand.

Provenance and peer review Not commissioned; externally peer reviewed.

Data sharing statement № additional data are available.
Open access This is an open access article distributed in accordance with the Creative Commons Attribution Non Commercial (CC BY-NC 4.0) license, which permits others to distribute, remix, adapt, build upon this work non-commercially, and license their derivative works on different terms, provided the original work is properly cited and the use is non-commercial. See: http://creativecommons.org/ licenses/by-nc/4.0/

(c) Article author(s) (or their employer(s) unless otherwise stated in the text of the article) 2018. All rights reserved. No commercial use is permitted unless otherwise expressly granted.

\section{REFERENCES}

1. Cameron SL, Taylor RW, Heath AL. Parent-led or baby-led? Associations between complementary feeding practices and healthrelated behaviours in a survey of New Zealand families. BMJ Open 2013;3:e003946.

2. Brown A, Lee M. A descriptive study investigating the use and nature of baby-led weaning in a UK sample of mothers. Matern Child Nutr 2011;7:34-47.

3. D'Andrea E, Jenkins K, Mathews M, et al. Baby-led Weaning: A Preliminary Investigation. Can J Diet Pract Res 2016;77:72-7.

4. Cameron SL, Heath AL, Taylor RW. Healthcare professionals' and mothers' knowledge of, attitudes to and experiences with, Baby-Led Weaning: a content analysis study. BMJ Open 2012;2:e001542.

5. Rapley G, Murkett T. Baby-led Weaning: Helping your Baby to Love Good Food. London: Vermillon, 2008.

6. Morison BJ, Taylor RW, Haszard JJ, et al. How different are baby-led weaning and conventional complementary feeding? A cross-sectional study of infants aged 6-8 months. BMJ Open 2016;6:e010665-11.

7. Domellöf M, Braegger C, Campoy C, et al. Iron requirements of infants and toddlers. J Pediatr Gastroenterol Nutr 2014;58:119-29.

8. Lozoff B, Beard J, Connor J, et al. Long-lasting neural and behavioral effects of iron deficiency in infancy. Nutr Rev 2006;64:34-43.

9. Congdon EL, Westerlund A, Algarin CR, et al. Iron deficiency in infancy is associated with altered neural correlates of recognition memory at 10 years. J Pediatr 2012;160:1027-33.

10. Taylor RW, Williams SM, Fangupo LJ, et al. Effect of a babyled approach to complementary feeding on infant growth and overweight: a randomized clinical trial. JAMA Pediatr 2017;171:838-46.

11. Fangupo LJ, Heath AM, Williams SM, et al. A Baby-Led Approach to Eating Solids and Risk of Choking. Pediatrics 2016;138:e20160772.

12. Daniels L, Heath AL, Williams SM, et al. Baby-Led Introduction to SolidS (BLISS) study: a randomised controlled trial of a baby-led approach to complementary feeding. BMC Pediatr 2015;15:1-15.

13. Ministry of Health New Zealand. Well Child/Tamariki Ora services. Wellington, 2014. http://www.health.govt.nz/our-work/life-stages/ child-health/well-child-tamariki-ora-services. (accessed 30 Jul 2017).

14. Cameron SL, Taylor RW, Heath AL. Development and pilot testing of Baby-Led Introduction to SolidS--a version of Baby-Led Weaning modified to address concerns about iron deficiency, growth faltering and choking. BMC Pediatr 2015;15:1-11.

15. Ministry of Health New Zealand. New Zealand food composition database. 2010 www.foodcomposition.co.nz/foodfiles (accessed 4 Jul 2014).

16. Ministry of Health New Zealand, University of Otago New Zealand. Methodology report for the 2008/09 New Zealand adult nutrition survey. Wellington: Ministry of Health, 2011. http://www.health.govt. nz/publication/methodology-report-2008-09-nz-adult-nutritionsurvey9-new-zealand-adult-nutrition-survey/oclc/756914555 (accessed 20 Apr 2017).

17. Clousten A. The role of commercial processed baby foods in the diets of New Zealand toddlers. New Zealand: Thesis, Master of Dietetics, University of Otago, 2014. http://hdl.handle.net/10523/ 5492

18. Dewey KG, Heinig MJ, Nommsen LA, et al. Adequacy of energy intake among breast-fed infants in the DARLING study: Relationships to growth velocity, morbidity, and activity levels. J Pediatr 1991;119:538-47.

19. Barris A. Meat and haem iron intakes of New Zealand toddlers aged 12-24 months. New Zealand: Thesis, Master of Dietetics, University of Otago, 2012. http://hdl.handle.net/10523/3839

20. Hartley N. Phytate and zinc intakes of toddlers from New Zealand. New Zealand: Thesis, Master of Dietetics, University of Otago, 2013. http://hdl.handle.net/10523/4645

21. Thurnham DI, McCabe LD, Haldar S, et al. Adjusting plasma ferritin concentrations to remove the effects of subclinical inflammation in 
the assessment of iron deficiency: a meta-analysis. Am J Clin Nutr 2010;92:546-55

22. Cogswell ME, Looker AC, Pfeiffer CM, et al. Assessment of iron deficiency in US preschool children and nonpregnant females of childbearing age: National Health and Nutrition Examination Survey 2003-2006. Am J Clin Nutr 2009;89:1334-42.

23. Harttig U, Haubrock J, Knüppel S, et al. The MSM program: webbased statistics package for estimating usual dietary intake using the Multiple Source Method. Eur J Clin Nutr 2011;65 (Suppl 1):S87-S91.

24. Gibson RS, Ferguson EL. An interactive 24-hour recall for assessing the adequacy of iron and zinc intakes in developing countries. HarvestPlus Technical Monograph 2008:1-160.

25. European Food Safety Authority (EFSA) Panel on Dietetic Products Nutrition and Allergies. Scientific Opinion on Dietary Reference Values for Iron, 2015:1-115.

26. Lombardi-Boccia G, Martinez-Dominguez B, Aguzzi A. Total Heme and Non-heme Iron in Raw and Cooked Meats. J Food Sci 2002;67:1738-41.

27. Szymlek-Gay EA, Ferguson EL, Heath AL, et al. Food-based strategies improve iron status in toddlers: a randomized controlled trial12. Am J Clin Nutr 2009;90:1541-51.

28. Olaya GA, Lawson M, Fewtrell MS. Efficacy and safety of new complementary feeding guidelines with an emphasis on red meat consumption: a randomized trial in Bogota, Colombia. Am J Clin Nutr 2013;98:983-93.

29. Walter T, Dallman PR, Pizarro F, et al. Effectiveness of iron-fortified infant cereal in prevention of iron deficiency anemia. Pediatrics 1993;91:976-82

30. Fox MK, Reidy K, Novak T, et al. Sources of energy and nutrients in the diets of infants and toddlers. J Am Diet Assoc 2006;106:28. e1-28.e25.

31. Wall CR, Brunt DR, Grant CC. Ethnic variance in iron status: is it related to dietary intake? Public Health Nutr 2009;12:1413-21.

32. European Food Safety Authority (EFSA) Panel on Contaminants in the Food Chain (CONTAM). Scientific Opinion on Arsenic in Food. EFSA Journal 2009;7:1351-199.
33. World Health Organization. Joint FAO/WHO Expert Committee On Food Additives: Summary and Conclusions, 2010:1-16.

34. Institute of Medicine,. Food and Nutrition Board. Dietary reference intakes: vitamin A, vitamin $K$, arsenic, boron, chromium, copper, iodine, iron, manganese, molybdenum, nickel, silicon, vanadium, and zinc. Washington, DC: National Academy Press, 2001.

35. World Health Organization. Iron deficiency anaemia: assessment, prevention and control: a guide for programme managers. Geneva: World Health Organization, 2001.

36. Southern Community Laboratories Ltd. Southern Community Laboratories Paediatric Reference Ranges: Southern Community Laboratories, 2014.

37. Gibson RS. Principles of Nutritional Assessment: Chapter 17 Assessment of iron status. 2nd ed. New York: Oxford University Press, 2005.

38. Domellöf M, Dewey KG, Lönnerdal B, et al. The diagnostic criteria for iron deficiency in infants should be reevaluated. $J$ Nutr 2002;132:3680-6.

39. Skinner JD, Carruth BR, Houck KS, et al. Longitudinal study of nutrient and food intakes of infants aged 2 to 24 months. J Am Diet Assoc 1997; 97:496-504.

40. Devaney B, Ziegler P, Pac S, et al. Nutrient intakes of infants and toddlers. J Am Diet Assoc 2004;104:14-21.

41. Ponza M, Devaney B, Ziegler P, et al. Nutrient intakes and food choices of infants and toddlers participating in WIC. J Am Diet Assoc 2004:104:71-9.

42. Briefel RR, Kalb LM, Condon E, et al. The Feeding Infants and Toddlers Study 2008: study design and methods. J Am Diet Assoc 2010;110:S16-S26.

43. Sharma S, Kolahdooz F, Butler L, et al. Assessing dietary intake among infants and toddlers 0-24 months of age in Baltimore, Maryland, USA. Nutr J 2013;12:1-7.

44. Atkinson J, Salmond C, Crampton P. NZDep2013 Index of Deprivation User's Manual. New Zealand: Department of Public Health, University of Otago, Wellington and Division of Health Sciences, University of Otago, 2014. 